\title{
On transcending the impasse of respiratory motion correction applications in routine clinical imaging - a consideration of a fully automated data driven motion control framework
}

\author{
Adam L Kesner ${ }^{1 *}$, Paul J Schleyer ${ }^{2}$, Florian Büther ${ }^{3}$, Martin A Walter ${ }^{4}$, Klaus P Schäfers ${ }^{3}$ and Phillip J Koo ${ }^{1}$
}

\footnotetext{
* Correspondence:

adam.kesner@ucdenver.edu

${ }^{1}$ Division of Nuclear Medicine, Department of Radiology, Anschutz Medical Campus, University of Colorado Denver, 12700 E 19th Ave, Box C-278, Aurora, CO 80045, USA Full list of author information is available at the end of the article
}

\begin{abstract}
Positron emission tomography (PET) is increasingly used for the detection, characterization, and follow-up of tumors located in the thorax. However, patient respiratory motion presents a unique limitation that hinders the application of high-resolution PET technology for this type of imaging. Efforts to transcend this limitation have been underway for more than a decade, yet PET remains for practical considerations a modality vulnerable to motion-induced image degradation. Respiratory motion control is not employed in routine clinical operations. In this article, we take an opportunity to highlight some of the recent advancements in data-driven motion control strategies and how they may form an underpinning for what we are presenting as a fully automated data-driven motion control framework. This framework represents an alternative direction for future endeavors in motion control and can conceptually connect individual focused studies with a strategy for addressing big picture challenges and goals.
\end{abstract}

Keywords: Respiratory gating; Motion correction; Motion control framework; Data-driven gating; Signal optimization; PET 


\section{Case presentation}

Over the last decade, a large body of work has been created developing equipment and strategies for respiratory motion control, primarily using gating $[2,10-12]$ or breath-hold approaches $[13,14]$. Integrated respiratory gating equipment and software are widely available today; research and clinical studies have shown the potential benefit of implementing motion control strategies; yet, despite positive research results, respiratory motion control is still rarely used in routine clinical imaging.

For the adoption and acceptance of motion control, strategies would, for practical considerations, require a favorable cost-to-benefit ratio to be established. Unfortunately, this goal is proving elusive. Respiratory motion control has, by nature, many casespecific factors and uncertainties involved in the gating process as well as the proceeding utilization of gated images, and this obfuscates efforts to characterize both the cost and benefit sides of the cost-benefit ratio. At present, the field lacks a unified vision for addressing this. It is with these considerations in mind that we present the idea that data-driven motion control strategies may have the requisite qualities to surmount this hurdle and drive this area of technology forward.

In the last decade, the main focus in this field has been set on establishing and utilizing hardware-based gating strategies. However, in parallel, some less known data-based methods have been developed and refined. These methods utilize untapped information contained in raw acquisition data for image enhancement. Unlike hardware, they can be run without any impact on image acquisition protocols. These strategies have evolved enough with respect to speed and accuracy that data-driven gating appears to have the capacity to perform comparably to hardware [15-18]. An example static positron emission tomography (PET) scan retrospectively gated using data-driven gating methods is shown in Figure 1, illustrating the qualitative and quantitative information this technology can provide with respect to characterizing metabolically active lesions.

Beyond the ability to replace hardware, data-driven algorithms can provide a foundation for an entirely new paradigm of motion control strategies, a paradigm in which we focus on minimal impact and maximal benefit at both ends of the best case scenario (images exhibit obvious benefit) and worst case scenario (effort provides no benefit) spectrum. This is achieved through the integration of both data-driven information capture and information utilization strategies into black box workflows. By expanding the application of motion control beyond highly specific, and potentially self-selective, research cohorts

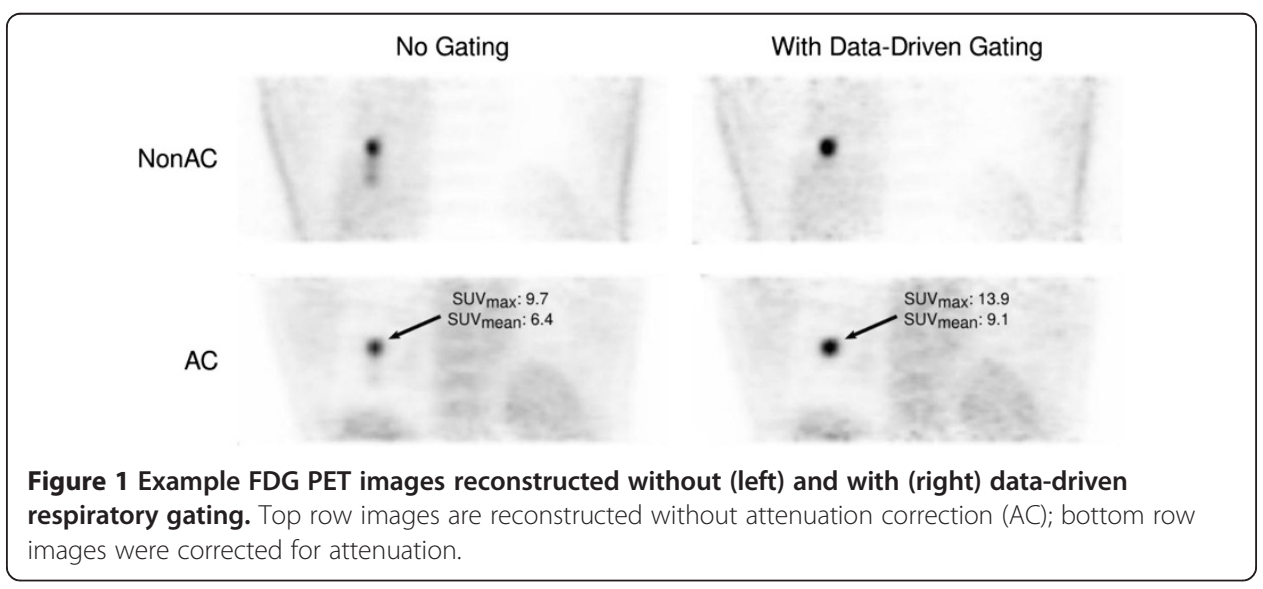


to general, non-specific imaging populations, we could address and ease the concern of whether gating will cause the potential degradation of images and subsequently patient care. To put it simply, the choice of whether to employ motion control could be made easy if the effort and risk of introducing it to clinical operations came close to nil and the potential benefit realization guaranteed. Patients move with different sound ambitious, it is a reasonable trajectory from the sub-field's current published achievements.

The characterization of a patient's breathing patterns is presently the only step in the motion control workflow which requires interruption of the traditional clinical workflow, when using vendor-supported hardware. Compared side by side, the implementation of data- and hardware-driven gating has some notable differences; this is illustrated in Table 1. A summary of listed data-driven gating achievements is shown in Table 2 and provides a snapshot of the field's establishment and progression towards greater speed, accuracy, and practicality.

We can note that most data-driven gating research to date has focused on respiratory and not on cardiac motion. One reason for this is that electrocardiography (ECG) signals, used for gating, work well. ECG gating is an established technology, relatively inexpensive, and reliable. Similar to respiratory motion correction, data driven cardiac gating may offer practical advantages and may be further developed in the future.

Beyond gating, there persists the question on how best to utilize gated data. Respiratory gating provides an uncertain value, particularly in general, non-specific populations. When applying gating, there is a fundamental tradeoff between the potential improved resolution and increased noise resulting from sub-sampled statistics, which affects detectability and contrast-to-noise. It is very difficult to predict who benefits, in what way, and who does not. Patients move in different patterns and to different extents, and available count statistics vary from patient to patient and scanner to scanner.

Table 1 Considerations for implementing different gating strategies

\begin{tabular}{|c|c|c|}
\hline & $\begin{array}{l}\text { Hardware-driven } \\
\text { strategies }\end{array}$ & $\begin{array}{c}\text { Data-driven } \\
\text { gating }\end{array}$ \\
\hline Requires changes to clinical image acquisition procedures & $x$ & \\
\hline Requires additional hardware & $x$ & \\
\hline Requires additional software & $x$ & $x$ \\
\hline Requires additional setup time & $x$ & \\
\hline Prone to setup error & $x$ & \\
\hline Information irrecoverable if acquisition error & $x$ & \\
\hline Decreases clinical throughput & $x$ & \\
\hline Requires additional training of technologists & $x$ & \\
\hline Increases radiation exposure to technologists & $x$ & \\
\hline May cause patient discomfort & $x$ & \\
\hline Require further establishment before routine clinical use & $x$ & $x$ \\
\hline Reproducible & & $\checkmark$ \\
\hline Operator independent & & $\checkmark$ \\
\hline Can be acquired and reacquired from an existing data set (if needed) & & $\checkmark$ \\
\hline Non-specific to scan/machine/institution & & $\checkmark$ \\
\hline Driven with internal motion & & $\checkmark$ \\
\hline
\end{tabular}


Table 2 Summary of publications/accomplishments in fully automated-data driven gating

\begin{tabular}{|c|c|c|c|c|c|c|c|c|}
\hline Year & Author & Journal/conference & Title & Summary & $\begin{array}{l}\text { Attenuation } \\
\text { correction }\end{array}$ & $\begin{array}{l}\text { Computer } \\
\text { to hardware }\end{array}$ & $\begin{array}{c}\text { Number of } \\
\text { patient scans }\end{array}$ & $\begin{array}{c}\text { Studied } \\
\text { radiotracers }\end{array}$ \\
\hline 2001 & Klein et al. [19] & IEEE workshop & $\begin{array}{l}\text { Fine-scale motion detection using } \\
\text { intrinsic list mode PET information }\end{array}$ & $\begin{array}{l}\text { Introduction of axial DD center-of-mass } \\
\text { strategy for respiratory motion } \\
\text { characterization in cardiac } \\
\text { imaging }\end{array}$ & Yes & Yes & 12 & FDG \\
\hline 2003 & Schleyer et. al. [20] & US patent & $\begin{array}{l}\text { Data driven motion correction for } \\
\text { nuclear imaging }\end{array}$ & $\begin{array}{l}\text { Introduction of DD masking strategy } \\
\text { for respiratory gating in NM imaging }\end{array}$ & No & No & - & - \\
\hline 2007 & Kesner et. al. [21] & $\begin{array}{l}\text { SNM annual } \\
\text { conference }\end{array}$ & $\begin{array}{l}\text { Respiratory gated PET based on } \\
\text { time activity curve analysis }\end{array}$ & $\begin{array}{l}\text { Introduction of DD sinogram voxel } \\
\text { fluctuation method }\end{array}$ & No & No & Sim & FDG \\
\hline 2008 & He et. al. [22] & IEEE TNS & $\begin{array}{l}\text { A novel method for respiratory } \\
\text { motion gated with geometric } \\
\text { sensitivity of the scanner in } \\
\text { 3D PET }\end{array}$ & $\begin{array}{l}\text { Introduction of DD geometric } \\
\text { sensitivity method }\end{array}$ & Yes & No & $1+\operatorname{sim}$ & FDG \\
\hline 2009 & Schleyer et. al. [23] & PMB & $\begin{array}{l}\text { Retrospective data-driven } \\
\text { respiratory gating for PET/CT }\end{array}$ & $\begin{array}{l}\text { Introduction of "spectral analysis" } \\
\text { approach to optimal signal } \\
\text { acquisition }\end{array}$ & Yes & Yes & 4 & FDG \\
\hline 2009 & Kesner et. al. [24] & IEEE TNS & $\begin{array}{l}\text { Respiratory gated PET derived } \\
\text { in a fully automated manner } \\
\text { from raw PET data }\end{array}$ & $\begin{array}{l}\text { Introduction of "image voxel } \\
\text { fluctuation" approach to optimal } \\
\text { signal acquisition }\end{array}$ & No & Yes & 24 & FDG \\
\hline 2009 & Büther et al. [25] & JNM & $\begin{array}{l}\text { List mode-driven cardiac } \\
\text { and respiratory gating in PET }\end{array}$ & $\begin{array}{l}\text { Comparison of multiple methods } \\
\text { for hardware- and data-driven } \\
\text { gating, also cardiac gating }\end{array}$ & No & Yes & 29 & FDG \\
\hline 2010 & Büther et. al. [15] & EJNMMI & $\begin{array}{l}\text { Detection of respiratory tumor } \\
\text { motion using intrinsic list } \\
\text { mode-driven gating in positron } \\
\text { emission tomography }\end{array}$ & $\begin{array}{l}\text { Extended GSG method, compared } \\
\text { multiple methods for gating }\end{array}$ & Yes & Yes & 34 & FDG \\
\hline 2010 & Kesner et. al. [26] & Medical Physics & $\begin{array}{l}\text { A new fast and fully automated } \\
\text { software based algorithm for } \\
\text { extracting respiratory signal } \\
\text { from raw PET data and its } \\
\text { comparison to other methods }\end{array}$ & $\begin{array}{l}\text { Introduced ultra-fast processing, } \\
\text { compared multiple methods for } \\
\text { gating }\end{array}$ & No & Yes & 22 & FDG \\
\hline
\end{tabular}


Table 2 Summary of publications/accomplishments in fully automated-data driven gating (Continued)

\begin{tabular}{|c|c|c|c|c|c|c|c|c|}
\hline 2011 & Schleyer et. al. [16] & PMB & $\begin{array}{l}\text { Extension of a data-driven } \\
\text { gating technique to 3D, } \\
\text { whole body PET studies }\end{array}$ & $\begin{array}{l}\text { Extended spectral analysis DD gating } \\
\text { method to 3D WB PET }\end{array}$ & Yes & Yes & 11 & FDG \\
\hline 2011 & Thielemans et. al. [27] & IEEE NSS-MIC & $\begin{array}{l}\text { Device-less gating for PET/CT } \\
\text { using PCA }\end{array}$ & $\begin{array}{l}\text { Use of PCA to extract respiratory } \\
\text { signal from raw PET and } C T\end{array}$ & No & Yes & 6 & $\mathrm{FDG}, \mathrm{FLT}$ \\
\hline 2013 & Büther et. al. [28] & EJNMMI & $\begin{array}{l}\text { External radioactive markers } \\
\text { for PET data-driven respiratory } \\
\text { gating in positron emission } \\
\text { tomography }\end{array}$ & $\begin{array}{l}\text { Compared multiple methods and } \\
\text { reexamined data driven gating } \\
\text { utilizing external markers }\end{array}$ & Yes & Yes & 30 & FDG \\
\hline 2013 & Kesner et. al. [18] & EJNMMI research & $\begin{array}{l}\text { Gating, enhanced gating, and } \\
\text { beyond: information utilization } \\
\text { strategies for motion management, } \\
\text { applied to preclinical PET }\end{array}$ & $\begin{array}{l}\text { Extended fast DD motion control } \\
\text { methods to preclinical PET, multiple } \\
\text { radiotracers, large subject population }\end{array}$ & No & Yes & 84 (rats) & $\begin{array}{l}\text { FDG, DMDPA, } \mathrm{NH}_{3} \\
\text { choline, } \mathrm{NaF}, \\
\text { FEDPMA, ML10 }\end{array}$ \\
\hline 2013 & Schleyer et. al. [29] & IEEE NSS-MIC 2013 & $\begin{array}{l}\text { Extracting a respiratory signal from } \\
\text { raw dynamic PET data that contain } \\
\text { tracer kinetics }\end{array}$ & $\begin{array}{l}\text { Extended data-driven gating to } \\
\text { dynamic PET/tracer kinetics }\end{array}$ & No & Yes & 53 & $\mathrm{NH}_{3}$ \\
\hline
\end{tabular}

Table does not include contributions from semi-automated algorithm innovators. DD = data driven. 
Different strategies for signal optimization and utilization have been in development in recent years, to limit image degradation caused by the gating processes. Automated data-driven methods can be used to combine separated gates [30], reconstruct data in four dimensions [31], with motion-driven super resolution techniques [9], or strategically filtered so as to only allow statistically supported frequencies to modify baseline ungated images, e.g., automated, on the fly quality assurance [18].

Data-driven motion characterization (gating) and signal utilization strategies can readily be combined into application workflows. The concept of building entire image processing workflows with exclusively data-driven components can provide elegant and complimentary solutions for the motion control process and is the basis for defining the data driven motion control framework. This framework could support low-impact solutions for motion control/additional information extraction and is exemplified in Figure 2. For example, the combination of data-driven gating and data-driven quality assurance strategies provides an approach to implement robust motion control through a process of extracting the motion information from raw PET data and using it only if, when, and where it adds value. This process has been shown to work smoothly, and fully automatically, in a population of traditional (non-gated) small-animal PET scans [18]. Presented here are examples, in Figure 3 and Additional files 1 and 2, showing that these workflows could readily be extended to thorax and whole body human imaging. Effectively, the scans or areas of scans that benefit from gating are gated. The scans that do not benefit from gating, because they contain no

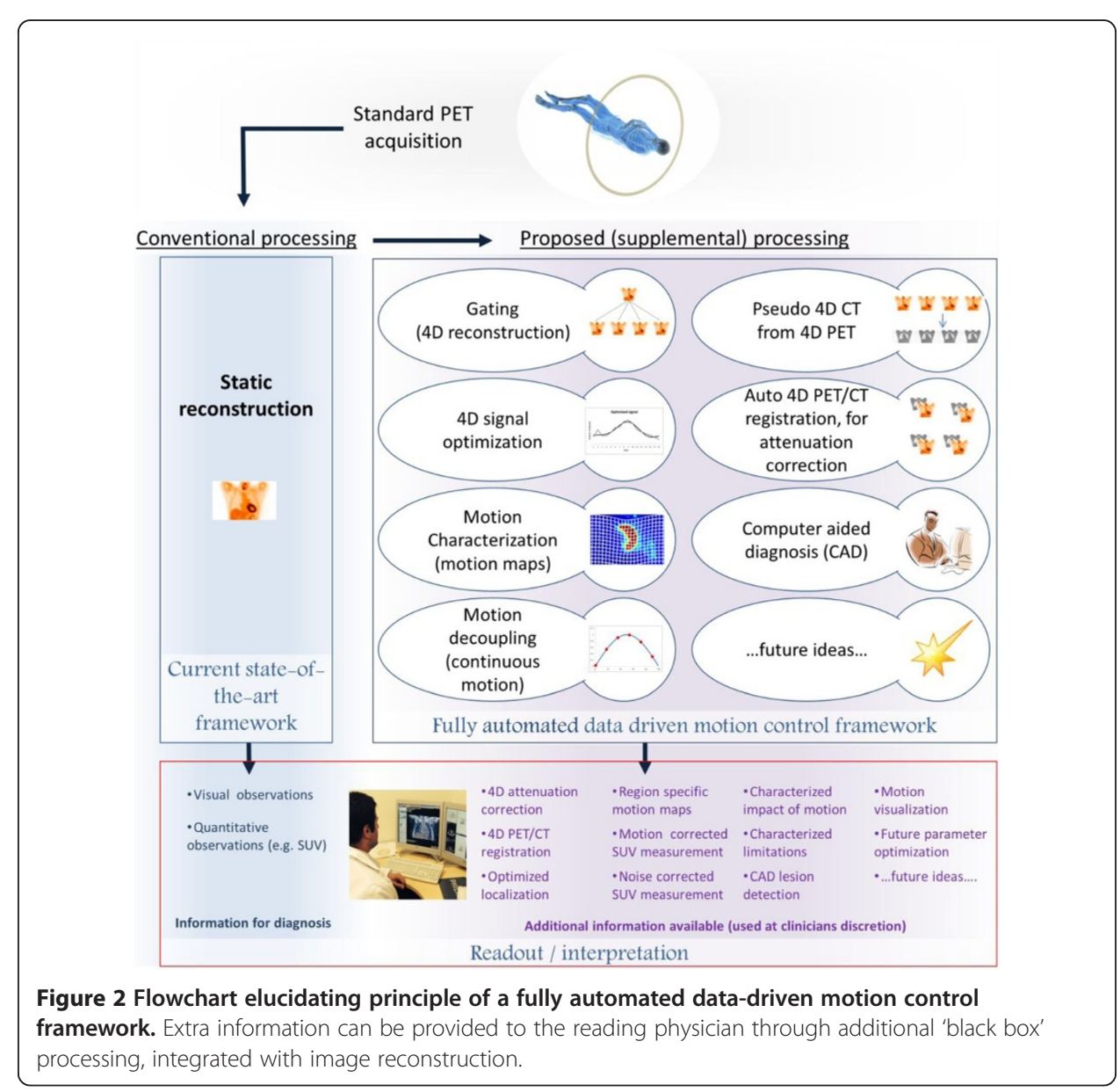




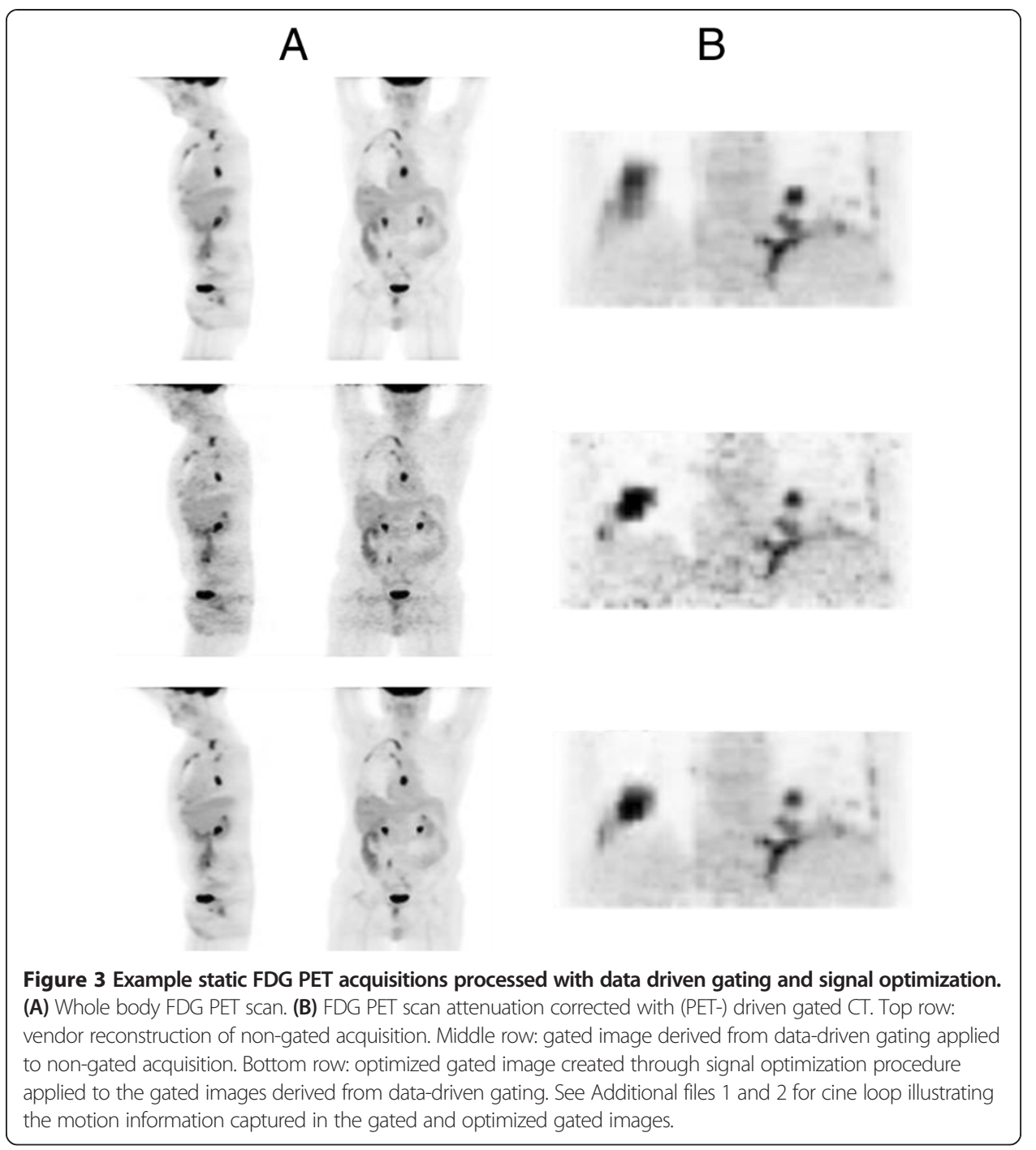

motion, erratic motion, or low count statistics, can be processed and automatically reverted back to their ungated (i.e., optimal) embodiment. Either way, enhanced images are created with no extra effort put in by patients and technologists and are available for consideration to the reading physicians for use at their discretion.

The future potential of data-driven motion control is promising; we have not seen limits on the information that can be extracted from data nor in the potential innovations that may be made within the automated software framework. We can envision the development of advanced information capture techniques coupled with iterative optimization procedures built to ensure maximum motion control benefit. Processing strategies can be built to support optimal gating/image reconstruction parameter determinations (for example number of gates), motion mapping, image morphing, computer-aided diagnosis (CAD), and continuous-over-time voxel value estimations (Additional files 1 and 2 and [18]). In another exciting direction, gated PET can be used to map static CT scans to PET gates, which in turn can be used to attenuation correct the gated PET, thereby facilitating gated PET and CT without deviating from standard PET-CT protocol (Additional file 2 and Figure 3B). These ideas can also be built to capitalize on the additional information 
available with new technologies, including time-of-flight PET and PET/magnetic resonance (MR). The resulting implications of ubiquitous data-driven motion control could be improved SUV measurements, localization, lesion detection and delineation, CAD applications, motion characterization, among other uses, - all while imposing no changes to routine imaging procedures.

This article is focused on the potential of combining data-driven technologies. However, it is worth noting also that development within the framework of data-driven motion control can readily extend and be integrated with hardware-based systems. For example, motion mapping, signal optimization, or PET-driven 4D CT modules can be used with hardware-gated scans as easily as they are used with data-driven scans. Furthermore, the developed ability to extract information from raw data may provide hybrid strategies in which data-driven and hardware-driven strategies support and/or back each other up.

The recent emergence of PET/MR technology is also relevant to the discussion of motion control and its future. MR units are capable of providing many kinds of information. Their integration with PET introduces new capacity for potentially robust motion correction. Advancements in this area of technology are already taking place [32,33]. However, it remains questionable how useful this technology will be for the majority of users in our field, as there are significant costs associated with purchasing, maintaining, and researching PET/MR. At the time of submission, vendor-supplied quotes indicated the price of a PET/MR system to be three times the cost of a TOF PET/CT system.

Data-driven gating and motion control stands in stark contrast to PET/MR with respect to its accessibility. In fact, this area uniquely presents an opportunity for advancing the state-of-the-art technology while decreasing the equipment requirements (and presumably monetary costs). In considering the cost of development, the fully automated data-driven motion control framework is a technology that readily can be developed and implemented within current infrastructures. Research data will come from existing scans and scanners. The entire data-driven sub-field is founded on the fact that there is real information embedded in PET data, information about motion, which is not currently being utilized. The accomplishments in Table 2 attest to this verity.

A recent review article written by Dao well summarizes in its title an opinion that is largely held in our field: 'Respiratory motion handling is mandatory to accomplish the high-resolution PET destiny' [8]. Similar sentiments, speaking to the need for practical motion control solutions, have been well articulated in a recent review article by our colleagues in radiation oncology: 'RG 4D-PET/CT seems to be a valuable tool in improving diagnostic performance of PET/CT and better defining the target volume for radiation therapy. However, its real benefit in routine clinical setting and its possible impact on patient management have not been established yet. In order to bring this technique into the normal workflow of a diagnostic imaging department, simple procedures for scanner setting, fast acquisition protocols and powerful reconstruction-processing algorithms are needed'. [34]. These ideas are shared by others as well [35]. It is clear that there is a desire to develop PET as a dependable 4D modality.

\section{Conclusions}

Respiratory motion has been acknowledged as a problem in nuclear medicine imaging, and there have been calls for the development of effective robust solutions for handling motion 
control. Data-driven motion control techniques are still only minimally developed, but may offer fast, inexpensive, and potentially robust systems to heed this call. This area can be developed with minimal resources, and one day may extend into the clinic with the assurance of no risk or changes to clinical procedures. To provide structure to this subfield's collective efforts and aspirations, we are presenting the concept of a fully automated data-driven motion control framework. This framework can provide a conceptual vehicle in which individual concentrated efforts in data-driven processing can readily be integrated into useful, coherent workflows with support a big picture strategy. Furthermore, this framework presents an alternative strategy for addressing the practical problems of respiratory motion in PET, a strategy based on developing low-impact and robust applications and should be appreciable by all stake holders: clinicians, researchers, vendors, and patients aline.

\section{Ethics statement}

All human studies presented in this communication have been approved by the appropriate ethics committees and have been performed in accordance with the ethical standards laid down in the 1964 Declaration of Helsinki and its later amendments. This included approval from the national ethics committee for data acquired at King's College, London, and the ethics committee of the University hospital of Münster, for the data acuired at the University hospital of Münster.

\section{Additional files}

Additional file 1: Whole body FDG PET scan motion animation. Top row: vendor reconstruction of non-gated acquisition. Middle row: gated image derived from data-driven gating applied to non-gated acquisition. Bottom row: optimized gated imagecreated through signal optimization procedure applied to the gated images derived from data-driven gating.

Additional file 2: FDG PET motion animation for PET- driven attenuation corrected data set. Top row: vendor reconstruction of non-gated acquisition. Middle row: gated image derived from data-driven gating applied to non-gated acquisition. Bottom row: optimized gated image created through signal optimization procedure applied to the gated images derived from data-driven gating. The gated images displayed were corrected for attenuation by generating a pseudo 4D CT attenuation map derived from 4D PET motion fields.

\section{Competing interest}

ALK and the Hebrew University hold a provisional patent for the signal optimization algorithm discussed in this paper.

\section{Author's contributions}

ALK contributed to the drafting of the manuscript and processing of data for figures. PJS contributed to drafting of the manuscript, acquiring data, and processing for the whole body PET figures. FB contributed to drafting of the manuscript, acquiring data, and processing for the gated PET/gated CT figures. MAW, KPS, and PJK contributed to drafting of the manuscript. All authors read and approved the final manuscript.

\section{Author details}

'Division of Nuclear Medicine, Department of Radiology, Anschutz Medical Campus, University of Colorado Denver, 12700 E 19th Ave, Box C-278, Aurora, CO 80045, USA. 'Division of Imaging Sciences and Biomedical Engineering, King's College London, London WC2R 2LS, UK. ${ }^{3}$ European Institute for Molecular Imaging, University of Münster, Münster 48149, Germany. ${ }^{4}$ Institute of Nuclear Medicine and Department of Clinical Research, University Hospital Bern, Bern 3010, Switzerland.

Received: 7 March 2014 Accepted: 23 May 2014

Published: 17 Jun 2014

References

1. Sureshbabu W, Mawlawi O: PET/CT imaging artifacts. J Nucl Med Technol 2005, 33:156-161. quiz 63-4.

2. Guerra L, De Ponti E, Elisei F, Bettinardi V, Landoni C, Picchio M, Gilardi MC, Versari A, Fioroni F, Dziuk M, Koza M, Ahond-Vionnet R, Collin B, Messa C: Respiratory gated PET/CT in a European multicentre retrospective study: added diagnostic value in detection and characterization of lung lesions. Eur J Nucl Med Mol Imaging 2012, 39:1381-1390. doi:10.1007/s00259-012-2148-2. 
3. Papathanassiou $D$, Becker $S$, Amir R, Meneroux B, Liehn JC: Respiratory motion artefact in the liver dome on FDG PET/CT: comparison of attenuation correction with CT and a caesium external source. Eur I Nucl Med Mol Imaging 2005, 32:1422-1428. doi:10.1007/s00259-005-1868-y.

4. Pevsner A, Nehmeh SA, Humm JL, Mageras GS, Erdi YE: Effect of motion on tracer activity determination in CT attenuation corrected PET images: a lung phantom study. Med Phys 2005, 32:2358-2362.

5. Lupi A, Zaroccolo M, Salgarello M, Malfatti V, Zanco P: The effect of ${ }^{18} \mathrm{~F}$-FDG-PET/CT respiratory gating on detected metabolic activity in lung lesions. Ann Nucl Med 2009, 23:191-196. doi:10.1007/s12149-008-0225-1.

6. Liu C, Pierce LA 2nd, Alessio AM, Kinahan PE: The impact of respiratory motion on tumor quantification and delineation in static PET/CT imaging. Phys Med Biol 2009, 54:7345-7362. doi:10.1088/0031-9155/54/24/007.

7. Callahan J, Kron T, Schneider-Kolsky M, Hicks RJ: The clinical significance and management of lesion motion due to respiration during PET/CT scanning. Cancer Imaging 2011, 11:224-236. doi:10.1102/1470-7330.2011.0031.

8. Daou D: Respiratory motion handling is mandatory to accomplish the high-resolution PET destiny. Eur J NuCl Med Mol Imaging 2008, 35:1961-1970. doi:10.1007/s00259-008-0931-x.

9. Wallach D, Lamare F, Kontaxakis G, Visvikis D: Super-resolution in respiratory synchronized positron emission tomography. IEEE Trans Med Imaging 2012, 31:438-448. doi:10.1109/TMI.2011.2171358.

10. Liu C, Alessio A, Pierce L, Thielemans K, Wollenweber S, Ganin A, Kinahan P: Quiescent period respiratory gating for PET/CT. Med Phys 2010, 37:5037-5043.

11. Bailey DL, Kalemis A: Externally triggered gating of nuclear medicine acquisitions: a useful method for partitioning data. Phys Med Biol 2005, 50:N55-N62. doi:10.1088/0031-9155/50/7/N02.

12. Werner MK, Parker JA, Kolodny GM, English JR, Palmer MR: Respiratory gating enhances imaging of pulmonary nodules and measurement of tracer uptake in FDG PET/CT. AJR Am J Roentgenol 2009, 193:1640-1645. doi:10.2214/AJR.09.2516.

13. Nagamachi S, Wakamatsu H, Kiyohara S, Fujita S, Futami S, Arita H, Nishii R, Tamura S, Kawai K: Usefulness of a deep-inspiration breath-hold ${ }^{18} \mathrm{~F}$-FDG PET/CT technique in diagnosing liver, bile duct, and pancreas tumors. Nucl Med Commun 2009, 30:326-332. doi:10.1097/MNM.0b013e3283298f78.

14. Torizuka T, Tanizaki Y, Kanno T, Futatsubashi M, Yoshikawa E, Okada H, Ouchi Y: Single 20-second acquisition of deep-inspiration breath-hold PET/CT: clinical feasibility for lung cancer. J Nucl Med 2009, 50:1579-1584. doi:10.2967/jnumed.109.064246.

15. Büther F, Ernst I, Dawood M, Kraxner P, Schäfers M, Schober O, Schäfers KP: Detection of respiratory tumour motion using intrinsic list mode-driven gating in positron emission tomography. Eur J Nucl Med Mol Imaging 2010, 37:2315-2327. doi:10.1007/s00259-010-1533-y.

16. Schleyer PJ, O'Doherty MJ, Marsden PK: Extension of a data-driven gating technique to 3D, whole body PET studies. Phys Med Biol 2011, 56:3953-3965.

17. Bundschuh RA, Martinez-Moller A, Essler M, Nekolla SG, Ziegler SI, Schwaiger M: Local motion correction for lung tumours in PET/CT-first results. Eur I Nucl Med Mol Imaging 2008, 35:1981-1988.

18. Kesner AL, Abourbeh G, Mishani E, Chisin R, Tshori S, Freedman N: Gating, enhanced gating, and beyond: information utilization strategies for motion management, applied to preclinical PET. EJNMMI Res 2013, 3:29. doi:10.1186/2191-219X-3-29.

19. Klein GJ, Reutter BW, Botvinick EH, Budinger TF, Huesman RH: Fine-scale motion detection using intrinsic list mode PET information. In Proceedings of the IEEE Workshop on Mathematical Methods in Biomedical Image Analysis (MMBIA'01). IEEE Computer Society; 2001:71.

20. Schleyer P, O'Keefe G, Scott A: Data driven motion correction for nuclear imaging. Google Patents; 2005.

21. Kesner A, Dahlbom M, Czernin J, Silverman DH: Respiratory gated PET based on time activity curve analysis. J Nucl Med meeting abstracts 2007, 48:416P.

22. He J, O'Keefe GJ, Jones G, Saunder T, Gong SJ, Moshi G, Scott AM: Evaluation of Geometrical Sensitivity for Respiratory Motion Gating by GATE and NCAT Simulation. In 29th Annual International Conference of the IEEE. Engineering in Medicine and Biology Society (EMBS); 2007:4165-4168.

23. Schleyer PJ, O'Doherty MJ, Barrington SF, Marsden PK: Retrospective data-driven respiratory gating for PET/CT. Phys Med Biol 2009, 54:1935-50.

24. Kesner AL, Bundschuh RA, Detorie NC, Dahlbom M, Ziegler SI, Czernin J, Silverman DH: Respiratory gated PET derived in a fully automated manner from raw PET data. IEEE Trans Nucl Sci 2009, 56:677-686.

25. Buther F, Dawood M, Stegger L, Wubbeling F, Schafers M, Schober O, Schafers KP: List mode-driven cardiac and respiratory gating in PET. J Nucl Med 2009, 50:674-681. doi:10.2967/jnumed.108.059204.

26. Kesner AL, Kuntner $\mathrm{C}: \mathrm{A}$ new fast and fully automated software based algorithm for extracting respiratory signal from raw PET data and its comparison to other methods. Med Phys 2010, 37:5550-5559.

27. Thielemans K, Rathore S, Engbrant F, Razifar P: Device-less gating for PET/CT using PCA. In Nuclear Science Symposium and Medical Imaging Conference (NSS/MIC). IEEE; 2011:3904-10.

28. Büther F, Ernst I, Hamill J, Eich HT, Schober O, Schäfers M, Schafers KP: External radioactive markers for PET datadriven respiratory gating in positron emission tomography. Eur J Nucl Med Mol Imaging 2013, 40:602-614. doi:10.1007/s00259-012-2313-7.

29. Schleyer PJ, Thielemans K, Marsden PK: Extracting a Respiratory Signal from Raw Dynamic PET Data that Contain Tracer Kinetics. Seoul: IEEE MIC; 2013 .

30. Dawood M, Büther F, Jiang X, Schäfers KP: Respiratory motion correction in 3-D PET data with advanced optical flow algorithms. IEEE Trans Med Imaging 2008, 27:1164-1175. doi:10.1109/TMI.2008.918321.

31. Grotus N, Reader AJ, Stute S, Rosenwald JC, Giraud P, Buvat I: Fully 4D list-mode reconstruction applied to respiratory-gated PET scans. Phys Med Biol 2009, 54:1705-1721. doi:10.1088/0031-9155/54/6/020

32. Chun SY, Reese TG, Ouyang J, Guerin B, Catana C, Zhu X, Alpert NM, El Fakhri G: MRI-based nonrigid motion correction in simultaneous PET/MRI. J Nucl Med 2012, 53:1284-1291. doi:10.2967/jnumed.111.092353. 
33. Wurslin C, Schmidt H, Martirosian P, Brendle C, Boss A, Schwenzer NF, Stegger L: Respiratory motion correction in oncologic PET using T1-weighted MR imaging on a simultaneous whole-body PET/MR system. J Nucl Med 2013, 54:464-471. doi:10.2967/jnumed.112.105296.

34. Bettinardi V, Picchio M, Di Muzio N, Gianolli L, Gilardi MC, Messa C: Detection and compensation of organ/lesion motion using 4D-PET/CT respiratory gated acquisition techniques. Radiother Oncol 2010, 96:311-316.

35. Visvikis D, Ell PJ: Impact of technology on the utilisation of positron emission tomography in lymphoma: current and future perspectives. Eur J Nucl Med Mol Imaging 2003, 30(Suppl 1):S106-S116. doi:10.1007/s00259-003-1168-3.

10.1186/2197-7364-1-8

Cite this article as: Kesner et al:: On transcending the impasse of respiratory motion correction applications in routine clinical imaging - a consideration of a fully automated data driven motion control framework. EJNMMI Physics 2014, 1:8

Submit your manuscript to a SpringerOpen ${ }^{\circ}$ journal and benefit from:

- Convenient online submission

- Rigorous peer review

- Immediate publication on acceptance

- Open access: articles freely available online

- High visibility within the field

- Retaining the copyright to your article 